\title{
1 Biotrickling filtration of isopropanol under intermittent loading conditions
}

2 Pau San-Valero, Josep M. Penya-Roja, Feliu Sempere and Carmen Gabaldón*

3 Research Group $G I^{2} A M$, Department of Chemical Engineering, University of Valencia, Avda. Universitat

$4 \quad$ s/n, 46100 Burjassot, Spain

5 *Corresponding author: Tel. +34 9635434 37, Fax: +34 9635448 98, E-mail address:

$6 \quad$ carmen.gabaldon@uv.es

\section{Abstract}

8 This paper investigates the removal of isopropanol by gas phase biotrickling filtration. Two plastic

9 packing materials, one structured and one random, have been evaluated in terms of oxygen mass transfer

10 and isopropanol removal efficiency (RE). Oxygen mass transfer experiments were performed at gas

11 velocities of 104 and $312 \mathrm{~m} \mathrm{~h}^{-1}$ and liquid velocities between 3 and $33 \mathrm{~m} \mathrm{~h}^{-1}$. Both materials showed

12 similar mass transfer coefficients up to liquid velocities of $15 \mathrm{~m} \mathrm{~h}^{-1}$. At greater liquid velocities, the

13 structured packing exhibited greater oxygen mass transfer coefficients. Biotrickling filtration experiments

14 were carried out at inlet loads (IL) from 20 to $65 \mathrm{~g} \mathrm{C} \mathrm{m}^{-3} \mathrm{~h}^{-1}$ and empty bed residence times (EBRT) from

1514 to $160 \mathrm{~s}$. To simulate typical industrial emissions, intermittent isopropanol loading (16 h/day, 5

16 day/week) and intermittent spraying frequency (15 min/1.5 hours) were applied. Maximum elimination

17 capacity (EC) of $51 \mathrm{~g} \mathrm{C} \mathrm{m}^{-3} \mathrm{~h}^{-1}$ has been obtained for the random packing (IL of $65 \mathrm{~g} \mathrm{C} \mathrm{m}^{-3} \mathrm{~h}^{-1}$, EBRT of

$1850 \mathrm{~s})$. The decrease in irrigation frequency to 15 min every 3 hours caused a decrease in the outlet

19 emissions from 86 to $59 \mathrm{mg} \mathrm{C} \mathrm{Nm}^{-3}$ (inlet of $500 \mathrm{mg} \mathrm{C} \mathrm{Nm}^{-3}$ ). The expansion of spraying to night and

20 weekend periods promoted the degradation of the isopropanol accumulated in the water tank during the

21 day, reaching effluent concentrations as low as $44 \mathrm{mg} \mathrm{C} \mathrm{Nm}^{-3}$. After a 7 week starvation period, the

22 performance was recovered in less than 10 days, proving the robustness of the process.

\section{Keywords}

24 biotrickling filter, intermittent loading, isopropanol, oxygen mass transfer, volatile organic compounds

\section{Introduction}

26 Isopropanol is one of the main solvents used in chemical industries, and its manufacture worldwide

27 exceeds $1 \times 10^{6}$ tonnes per year. This results in a significant production of solvent organic wastes,

28 including emissions to the atmosphere as volatile organic compounds (VOC). Since the abatement of 
VOC is a factor in the protection of the environment and of public health in Europe [1], treatment technologies for VOC removal are required. When emissions are characterised by high flow rates and low VOC concentrations, biotreatments are suitable alternatives to conventional physicochemical technologies, and have been classified as best available technologies (BAT) [2] owing to their low operational costs and the minimisation of negative cross-media effects [3]. Compared to a conventional biofilter, a biotrickling filter (BTF) allows better control of the physicochemical parameters, offers a smaller footprint and higher removal rates. The BTF uses an inert packing material and involves the continuous or intermittent trickling of water. In this configuration, the biomass attaches to the media and develops a biofilm, thus the pollutant and the oxygen must be transferred from the gas phase to the trickling liquid and then to the biofilm, where the biodegradation takes place.

To enhance the performance of the BTF it is necessary to understand the rate limiting steps of the process. One of the most important limiting factors may be the mass transfer from gas to liquid and biofilm [4-6]. However, correlations commonly used for absorption in chemical processes do not correctly represent the phenomenon occurring in BTFs due to the different hydrodynamic conditions of chemical absorption. Absorption is marked by higher superficial velocities of the gas and liquid in comparison with BTF [7]. Treatment of hydrophilic compounds such as isopropanol, characterised by low Henry`s constants, could typically be limited by oxygen transference. Consequently, oxygen mass transfer should be systematically studied in these cases [7].

Despite being widely used in industrial and chemical processes, there are no previous studies on the removal of isopropanol by biotrickling filtration. Literature data about the removal of isopropanol by biofilters is also scarce compared with other solvents $[8,9]$. These works have been performed under continuous and constant loading; the removal of isopropanol under oscillating and/or discontinuous emissions has not been previously reported. Most gaseous emissions from industrial processes are intermittently generated due to short-time shut off periods during the night and/or weekends. In fact, previous studies show that the operation of biofiltration under discontinuous VOC feeding regime can produce a degeneration of the system's performance, although the literature in this field is still limited. Cox and Deshusses [10] reported that non-use periods cause a starvation condition on the microorganisms, which has been identified as one of factors that causes a reduction in pollutant removal. 
These researchers observed that after 2 days of starvation, the endogenous respiration activity dropped by about $60 \%$ and remained relatively constant thereafter.

The influence of long term starvation periods, without VOC feeding, also requires further study to advance the applicability of this technology. In our previous work, the reacclimation period, after 3 weeks without VOC feeding, was lower than 24 hours working at $60 \mathrm{~s}$ of EBRT in a BTF treating a mixture of ethanol, ethyl acetate and methyl-ethyl ketone (MEK), and operating under discontinuous loading [11].

\section{6}

The purpose of the present research was to investigated the removal of isopropanol using a BTF, taking into consideration the following objectives: (1) to determine the oxygen mass transfer coefficient of a structured and a random packing material, establishing a relationship between the mass transfer coefficient, the trickling flow rate and the specific surface area; (2) to compare the performance of the process, in terms of EC and RE, under isopropanol discontinuous loading conditions at several EBRT by using two BTFs operating in parallel, one filled with the structured and the other with the random material; (3) to evaluate the influence of spraying frequency on the RE, and (4) to evaluate the response of the BTFs to a long term starvation period representative of a holiday closure at an industrial site.

\section{Materials and methods}

The system consisted of a column of methacrylate $(14.4 \mathrm{~cm}$ internal diameter, $80 \mathrm{~cm}$ height $)$ and a recirculation tank (10 L of water volume). The schematic of the experimental set-up is shown in Fig. 1. The column was filled with two inert packing materials: a novel plastic cross-flow structured packing material (Odourpack, Pure Air Solution, The Netherlands) with $410 \mathrm{~m}^{2} \mathrm{~m}^{-3}$ of specific surface area, and a random packing material (Refill-Tech, Italy) consisting of polypropylene rings with a nominal diameter of 5/8" and a specific surface area of $348 \mathrm{~m}^{2} \mathrm{~m}^{-3}$. The packing height was $20 \mathrm{~cm}$ for the structured packing

83 and $40 \mathrm{~cm}$ for the rings. The air stream (compressed, filtered and dried) was introduced through the 84 bottom of the columns, with the flow rate adjusted using a mass flow controller (Bronkhorst Hi-Tec, The

85 Netherlands). The experiments were carried out at two air superficial velocities of $104 \mathrm{~m} \mathrm{~h}^{-1}$ and $312 \mathrm{~m} \mathrm{~h}^{-}$

$86{ }^{1}$. The trickling water was recirculated using a centrifugal pump (HPR10/15, ITT, Great Britain) in 
87 counter current mode with respect to the air flow rate, with a superficial velocity of the water between 3

88 and $33 \mathrm{~m} \mathrm{~h}^{-1}$. The equipment is completed with a dissolved oxygen probe (Cellox® 325i, WTW,

89 Germany). An internal pump installed in the recirculation tank ensured the ideal mixing condition. The

90 experiments were carried out at room temperature $\left(21.2 \pm 0.7^{\circ} \mathrm{C}\right)$.

91

92 For the determination of $k_{L} a$ a dynamic method under inert conditions was used. The method consists of

93 measuring the increase of the oxygen concentration with time in a tank in which the oxygen has been

94 previously displaced by bubbling nitrogen gas. The experiment starts when the air blower and the

95 recirculation pump are switched on; oxygen is transferred from the air to the water in the packed column

96 causing an increase in the dissolved oxygen concentration in the recirculation tank. Under these

97 conditions, oxygen mass balances are as follows:

98 - In the packed column:

99

$$
\text { Cout }=C^{*}-\frac{C^{*}-C}{\exp \left(\frac{L}{v} k_{L} a\right)}
$$

100

(1)

101 where $C_{\text {out }}$ is the predicted dissolved oxygen concentration at the bottom of the column, $C$ is the predicted

102 dissolved oxygen concentration in the recirculation tank, $C^{*}$ is the oxygen solubility and $L$ and $v$ are the

103 height of the column and the velocity of the trickling water, respectively.

$104 \quad$ - In the tank:

$105 \frac{d C}{d t}=\frac{1}{\theta}($ Cout $-C)$

106 where $\theta$ is the residence time in the tank.

107 The combination of Eqs (1) and (2) permits to obtain the variation of the predicted oxygen concentration 108 with time:

$109 \quad \frac{d C}{d t}=\frac{1}{\theta}\left(C^{*}-\left(\frac{C^{*}-C}{\exp \left(\frac{L}{v} k_{L} a\right)}-C\right)\right)$ 
110 Due to the dynamics of the probe is not fast enough, it is necessary to take into account the response time

111 constant of the probe, $\tau$, defined as time that the probe achieves $63 \%$ of the end value measured when the

112 probe is subjected to a step input assay [12]. The response time of the probe was determined by

113 transferring the oxygen probe from an ideal mixed tank in which the dissolved oxygen concentration was

114 displaced by bubbling nitrogen gas to a second tank which is saturated with dissolved oxygen. It was

115 assumed a first order dynamic according to Eq. (4) [13].

$116 \frac{d C_{m}}{d t}=\frac{\left(C-C_{m}\right)}{\tau}$

117 where $C_{m}$ is the measured dissolved oxygen concentration in the recirculation tank by the oxygen probe.

118 The value of $k_{L} a$ of the packed column was calculated by minimising the sum of squares of the difference

119 between the measured data recorded for dissolved oxygen concentration in the recirculation tank and the

120 value obtained from the mathematical resolution of Eqs. (3) and (4).

121 Experimental set-up for the removal of isopropanol

122 The experiment was performed using two identical laboratory-scale BTFs operating in parallel, named

123 BTF1 and BTF2. The experimental set-up is shown in Fig. 2. Each bioreactor was composed of three

124 cylindrical methacrylate modules in series, with a total bed length of $100 \mathrm{~cm}$ and an internal diameter of

$12514.4 \mathrm{~cm}$. BTF1 was filled with the structured material and BTF2 with the random packing, in each using a

126 volume of $16.32 \mathrm{~L}$. The bioreactors were also provided with $20 \mathrm{~cm}$ of top and bottom free spaces. The

127 stream contaminated with isopropanol was introduced through the bottom of the column of the BTFs. A

128 recirculation solution of $3 \mathrm{~L}$, partially renewed every week, was fed into the bioreactor in counter-current

129 mode with respect to the air flow using a centrifugal pump at $2.5-3 \mathrm{~L} \mathrm{~min}^{-1}$. A nutrient solution buffered

130 at pH $7\left(21.65 \mathrm{~g} \mathrm{KNO}_{3} \mathrm{~L}^{-1}, 4.6 \mathrm{~g} \mathrm{Na}_{3} \mathrm{PO}_{4} \cdot 12 \mathrm{H}_{2} \mathrm{O} \mathrm{L}{ }^{-1}\right.$ and $\mathrm{Ca}, \mathrm{Fe}, \mathrm{Zn}, \mathrm{Co}, \mathrm{Mn}, \mathrm{Na}, \mathrm{Ni}, \mathrm{B}, \mathrm{I}, \mathrm{Se}, \mathrm{Cr}, \mathrm{Cu}$ and

131 vitamins at trace doses) was supplied to the recirculation tank using a peristaltic pump. The nutrient

132 solution flow rate was set to maintain a supplied mass ratio of carbon and nitrogen $(\mathrm{C} / \mathrm{N})$ of 35 , in order

133 to assure that the nitrogen concentration in the recirculation solution was not limiting the biodegradation

134 process. $\mathrm{C} / \mathrm{N}$ mass ratios between 13 and 70 are suggested in the literature for the operation of bioreactors

135 [14]. 
137 The operation of the bioreactors to determine the influence of IL and EBRT on the removal of

138 isopropanol was structured in three phases (A, B, C) of a 2-fold step decrease in inlet concentration, phase

139 A started with $1000 \mathrm{mg} \mathrm{C} \mathrm{Nm}^{-3}$. For each phase, several 1.8-fold IL step increases were carried out,

140 resulting in EBRTs from 15 to $160 \mathrm{~s}$. The design parameters of the experiments are summarised in Table

141 1. Intermittent feeding of VOC was programmed to simulate shift working conditions, which consisted in

142 a regime of a period with VOC feeding of 16 hours per day (from 6:00 to 22:00 h) for 5 days at week, and

143 night and weekend periods without VOC supply. The air flow rate was kept constant during both periods.

144 Trickling water of 15 minutes every 1.5 hours was set during the VOC feeding period. During non-VOC

145 feeding periods, the trickling water was stopped.

146 Influence of spraying frequency on the removal of isopropanol

147 The influence of the spraying frequency on the global performance of the system was evaluated by testing

148 several patterns at an IL of $30 \mathrm{~g} \mathrm{C} \mathrm{m}^{-3} \mathrm{~h}^{-1}$ and EBRT of $60 \mathrm{~s}$ on the random packing material. Three

149 frequency regimes were tested. Two of them were only applied during VOC feeding (16 hours per day, 5

150 days per week) with trickling water frequencies of 15 minutes every 1.5 hours or 15 minutes every 3

151 hours, spraying was stopped during the night and weekend periods. The expansion of spraying to the non-

152 VOC feeding periods was tested by trickling 15 minutes every 3 hours over the whole day (24 hours per

153 day, 7 days per week).

154 Influence of long-term starvation on the removal of isopropanol

155 The influence of a long period without VOC feeding on the performance of the BTF was evaluated by

156 stopping the supply of isopropanol for a period of 7 weeks. During this time, the air flow rate was

157 maintained at an EBRT of $60 \mathrm{~s}$, and the water trickling was set to 15 minutes per day, to provide the

158 minimum amount of nutrients and moisture that assures biomass viability. After that, the supply of

159 isopropanol was restored using the same discontinuous VOC feeding mode (16 hours per day, 5 days per

160 week) that was applied before the VOC interruption; IL of $35 \mathrm{~g} \mathrm{C} \mathrm{m}^{-3} \mathrm{~h}^{-1}$, EBRT of $60 \mathrm{~s}$ and a trickling

161 water frequency of 15 minutes every 4 hours was set.

162 Analytical methods 
163 The oxygen concentration in the liquid was determined using a dissolved oxygen probe (Cellox ${ }^{\circledR} 325 \mathrm{i}$,

164 WTW, Germany). The concentration of isopropanol was measured using a total hydrocarbon analyzer

165 (Nira Mercury 901, Spirax Sarco, Spain). The response factor of the total hydrocarbon analyzer was

166 determined by gas chromatograph (model 7890, Agilent Technologies, EEUU). The $\mathrm{CO}_{2}$ concentration

167 was analysed using a nondispersive infrared carbon dioxide analyzer (GMP222, Vaisala, Finland). The

168 inlet and outlet gas streams were monitored daily. The pressure drop was monitored daily (MP101, KIMO

169 Instruments, Spain). To determine the quality of the recirculation solution, conductivity and $\mathrm{pH}$ (ph/Cond

170 340i, WTW, Germany), soluble chemical oxygen demand (COD), nitrate and suspended solids (SS)

171 concentrations were measured prior to the weekly purge. Soluble COD and nitrate concentrations were

172 measured using Merck Speqtroquant kits (Merck KGaA, Germany): 114540 (COD) and 114773 (nitrate).

173 The SS concentrations were determined according to the Standard Methods for Examination of Water and

174 Wastewaster [15].

\section{Results and discussion}

176 Determination of oxygen mass transfer coefficients

177 The determination of oxygen mass transfer coefficients was carried out for the two packing materials at

178 several liquid velocities. The $k_{L} a$ coefficients were obtained using the least squares method in order to

179 minimise the differences between the experimental data and the concentration of oxygen provided by the

180 simple mathematical model established by Eqs. (3) and (4). The response time of the probe $(\tau)$ was

181 determined earlier by means of a step input assay, resulting in a value of $19.4 \pm 1.5 \mathrm{~s}$. The effect of liquid

182 velocity on mass transfer is shown in Fig. 3. The two packing materials presented a relationship between

183 the liquid flow rate and the $k_{L} a$ values for a gas velocity of $104 \mathrm{~m} \mathrm{~h}^{-1}$ with similar values up to $15 \mathrm{~m} \mathrm{~h}^{-1}$.

184 For liquid velocities higher than this value, the structured material showed greater values of $k_{L} a$. That

185 difference cannot be explained by the slightly higher specific surface area of this material alone, it could

186 be attributed to the different air and water flow paths in both materials. Selecting a liquid velocity of $10 \mathrm{~m}$

$187 \mathrm{~h}^{-1}$ as representative of the operation of the BTFs in this study, a $k_{L} a$ approximately of $45 \mathrm{~h}^{-1}$ was obtained

188 for both packing materials, without differences between them. The values obtained herein are of the same

189 order of magnitude as those found by Kim and Deshusses [7] in previous papers. These authors reported a

190 value of about $25 \mathrm{~h}^{-1}$ for liquid velocities around $10 \mathrm{~m} \mathrm{~h}^{-1}$ using 1 " Pall rings $\left(210 \mathrm{~m}^{2} \mathrm{~m}^{-3}\right)$. These authors 
191 showed that Onda's correlation overestimated the $k_{L} a$ values on biotrickling filtration by a factor of about

19220 [16], indicating the need for determining oxygen mass transfer in the typical range of velocities of

193 biotreatments.

194

195 The influence of gas velocity on the oxygen mass transfer coefficients has been determined with an

196 additional test conducted at a gas velocity of $312 \mathrm{~m} \mathrm{~h}^{-1}$. As an example, the results obtained for the

197 structured packing material are shown in Fig. 4. As can be expected, these experiments demonstrate that

$198 k_{L} a$ values were not significantly affected by gas velocities in the typical values of operation of BTFs.

199 Influence of inlet load and EBRT on the removal of isopropanol

200 The influence of inlet load on the removal of isopropanol in terms of EC and RE was evaluated. To

201 simulate the emissions of industrial facilities, an intermittent VOC loading regime and a discontinuous

202 trickling pattern was used. As an example, 24 hours of a typically daily evolution of VOC concentration

203 in the outlet gas stream of the BTF2 is shown in Fig. 5. This figure represents the outlet emission pattern

204 for two different stages where inlet concentrations of $1000 \mathrm{mg} \mathrm{C} \mathrm{Nm}^{-3}$ (IL of $65 \mathrm{~g} \mathrm{C} \mathrm{m}^{-3} \mathrm{~h}^{-1}$, stage A-III,

205 Fig. 5a) and $500 \mathrm{mg} \mathrm{C} \mathrm{Nm}^{-3}$ (IL of $35 \mathrm{mg} \mathrm{C} \mathrm{m}^{-3}$, stage B-II, Fig. 5b) were applied. As can be observed,

206 the operating regime resulted in peaks of concentration coinciding with the irrigation of the bed (15

207 minutes every 1.5 hours). These peaks are related to the accumulation of the pollutant in the trickling

208 water and subsequent desorption when trickling starts, resulting in outlet emission peaks. The comparison

209 between both stages shows the influence of loading in the emission pattern. In the periods between

210 trickling, a complete removal of pollutant was achieved for the lowest loading condition (Fig. 5b), while

211 leakage of pollutant occurred for the highest load (Fig. 5a).

212

213 The monitoring of the quality of the trickling water was carried out twice per week for the whole

214 experimental period. Average values along with the standard deviation are shown in Table 2. As shown

215 in Table 2, the $\mathrm{pH}$ and conductivity were kept in normal values for the development of the biological

216 process during the whole period. Nitrate in the water tank was kept above $10 \mathrm{mg} \mathrm{N} \mathrm{L}^{-1}$ assuring that

217 nutrients were not limiting the bioprocess. Soluble COD values ranged between $700-1800 \mathrm{mg} \mathrm{COD} \mathrm{L}^{-1}$

218 depending on the loading conditions. The operational protocols regarding the quality of the trickling 
219 water included a weekly purge of $1.5 \mathrm{~L}$ of water. In all cases, solvent removal with the purge represents

220 less than $5 \%$ of the total amount of fed isopropanol during the week. In consequence, the organic carbon

221 in the purge was considered negligible for evaluation of the BTF performance in terms of inlet load (IL),

222 elimination capacity (EC) and removal efficiency (RE). About suspended solids, concentrations higher

223 than $500 \mathrm{mg} \mathrm{L}^{-1}$ were only observed since month 3, indicating that significant detachment of solids from

224 the packing materials started as the biofilm thickened. Average values of the suspended solids

225 concentration from day 90 until the end of the experimentation period resulted in $3151 \mathrm{mg} \mathrm{L}^{-1}$ and 1022

$226 \mathrm{mg} \mathrm{L}^{-1}$ for BTF1 and BTF2, respectively. The higher suspended solid concentrations in BTF1 than in

227 BTF2 can be associated with the capability of the structured packing material to drag the biomass, in

228 comparison with the random packing where biomass is detached with greater difficulty. In both

229 bioreactors, the pressure drop was kept below $48 \mathrm{~Pa} \mathrm{~m}^{-1}$, indicating that non excessive accumulation of

230 biomass occurred. The accumulation of acetone as an intermediate product was not observed.

232 To quantify of the outlet concentration of VOC, the most unfavourable conditions were selected. So, the

233 average values of the previous 7 hours during VOC feeding (from 15:00 to 22:00 h: last five spraying

234 cycles) was used. The performance of BTF1 and BTF2 is shown in Fig. 6a and Fig. 6b, respectively. A

235 similar evolution of both BTFs during the whole experiment was observed. The start-up was carried out

236 using activated sludge from the secondary clarifier of the municipal wastewater treatment plant of Carlet

237 (Spain). In order to simulate the procedure of the industrial BTFs, the inoculum was not previously

238 adapted to degrade isopropanol. The systems were started by setting an EBRT of $160 \mathrm{~s}$ for BTF1 and 152

239 s for BTF2 and an inlet concentration of $1000 \mathrm{mg} \mathrm{C} \mathrm{Nm}^{-3}$ (phase A-I , day 0-48). After 4-6 days of

240 operation, REs of $70 \%$ were obtained. After that the performance was stable, with REs around $80 \%$ for

241 both BTFs. On day 49 (phase A-II) and on day 70 (phase A-III) the EBRT was consecutively decreased to

24290 and $50 \mathrm{~s}$, increasing the IL to 35 and $65 \mathrm{~g} \mathrm{C} \mathrm{m}^{-3} \mathrm{~h}^{-1}$, respectively. During these stages, both BTFs

243 presented similar variability in their performance with REs ranging between 60 and $85 \%$. In phase B, an

244 inlet concentration of $500 \mathrm{mg} \mathrm{C} \mathrm{Nm}^{-3}$ was set. REs greater than $90 \%$ were achieved by applying ILs of

24518 (phases B-I, days 91-97) and $33 \mathrm{~g} \mathrm{C} \mathrm{m}^{-3} \mathrm{~h}^{-1}$ (phase B-II, days 98-104). In phase B-III (days 105-125),

246 with an IL of $64 \mathrm{~g} \mathrm{C} \mathrm{m}^{-3} \mathrm{~h}^{-1}$, the REs significantly decreased to 60-70\%. Finally, the inlet concentration

247 applied in phase $\mathrm{C}$ was $250 \mathrm{mg} \mathrm{C} \mathrm{Nm}^{-3}$. Working with an IL of $37 \mathrm{~g} \mathrm{C} \mathrm{m}^{-3} \mathrm{~h}^{-1}$ for BTF1, and $39 \mathrm{~g} \mathrm{C} \mathrm{m}^{-3} \mathrm{~h}^{-}$ 
$248{ }^{1}$ for BTF2 (days 126-132), high REs with values around $80 \%$ for BTF1 and $88 \%$ for BTF2, were 249 observed. When the IL was increased to $65 \mathrm{~g} \mathrm{C} \mathrm{m}^{-3} \mathrm{~h}^{-1}$ (days 133-163), the performance of the BTFs 250 decreased to reach a RE of $49 \%$ for BTF1 and $60 \%$ for BTF2, coinciding with the minimum EBRT applied (14 s).

252

253

The elimination capacity versus the inlet load is presented in Fig. 7 for the different EBRTs (BTF1 in Fig.

$2547 \mathrm{a}$, BTF2 in Fig. 7b). Both BTF performed near complete degradation up to a critical IL of $30 \mathrm{~g} \mathrm{C} \mathrm{m}^{-3} \mathrm{~h}^{-1}$ 255 for all tested inlet concentrations (EBRT>25s). Maximum ECs of $44.7 \pm 5.3 \mathrm{~g} \mathrm{C} \mathrm{m}^{-3} \mathrm{~h}^{-1}$ and $50.8 \pm 3.4 \mathrm{~g}$

$256 \mathrm{C} \mathrm{m}^{-3} \mathrm{~h}^{-1}$ were obtained for BTF1 and BTF2 respectively (IL of $65 \mathrm{~g} \mathrm{C} \mathrm{m}^{-3} \mathrm{~h}^{-1}$ and EBRT of $50 \mathrm{~s}$ ).

258 No data related to the biodegradation of isopropanol under intermittent loading conditions has previously been published in the literature. Previous studies on the removal of isopropanol under continuous loading conditions are also scarce, and correspond with biofilters and trickled bed biofilters. Chang and $\mathrm{Lu}[8]$ found ECs between 45-89 $\mathrm{g} \mathrm{C} \mathrm{m}^{-3} \mathrm{~h}^{-1}$ for isopropanol loadings of 50-90 $\mathrm{g} \mathrm{C} \mathrm{m}^{-3} \mathrm{~h}^{-1}$ with EBRT of 20-30

262 s. Krailas et al. [9] reported a maximum isopropanol elimination capacity of $276 \mathrm{~g} \mathrm{~m}^{-3} \mathrm{~h}^{-1}$ (equivalent to $263165 \mathrm{~g} \mathrm{C} \mathrm{m}^{-3} \mathrm{~h}^{-1}$ ) and an acetone production rate of $56 \mathrm{~g} \mathrm{~m}^{-3} \mathrm{~h}^{-1}$ (equivalent to $35 \mathrm{~g} \mathrm{C} \mathrm{m}^{-3} \mathrm{~h}^{-1}$ ) at an inlet 264 load of $342 \mathrm{~g} \mathrm{~m}^{-3} \mathrm{~h}^{-1}$ (equivalent to $204 \mathrm{~g} \mathrm{C} \mathrm{m}^{-3} \mathrm{~h}^{-1}$ ) using a biofilter. As can be seen, data reported in the present study show lower values of EC than those from the literature, due to the discontinuous operation used to mimic an industrial pattern. Results can also be compared with the removal of other hydrophilic compounds by biotrickling filtration, such ethanol. Working under continuous loading conditions, Cox et al. [17] found a critical IL of $70 \mathrm{~g}$ ethanol $\mathrm{m}^{-3} \mathrm{~h}^{-1}$ (equivalent to $37 \mathrm{~g} \mathrm{C} \mathrm{m}^{-3} \mathrm{~h}^{-1}$ ) at an EBRT of $57 \mathrm{~s}$, and Morotti et al. [18] determined a maximum EC of $46 \mathrm{~g}$ ethanol $\mathrm{m}^{-3} \mathrm{~h}^{-1}$ (equivalent to $24 \mathrm{~g} \mathrm{C} \mathrm{m}^{-3} \mathrm{~h}^{-1}$ ) using an EBRT of $66 \mathrm{~s}$ and an inlet concentration of $1100 \mathrm{mg}$ ethanol $\mathrm{m}^{-3}$. Working under intermittent loading conditions, there are limited studies with BTF. In our previous work [19], a maximum EC of $48.5 \mathrm{~g} \mathrm{C} \mathrm{m}^{-3}$

$272 \mathrm{~h}^{-1}$ was obtained with an IL of $70.5 \mathrm{~g} \mathrm{C} \mathrm{m}^{-3} \mathrm{~h}^{-1}$ and an EBRT of $40 \mathrm{~s}$ treating a mixture 1:1 of ethyl acetate

273 and ethanol working with fluctuating conditions for 12 hours per day, 5 days at week using 1"

274 polypropylene rings as the packing material. Thus, the data presented in the present work is comparable

275 with those previously reported for the fluctuating conditions of other oxygenated solvents, showing the

276 capability of the system to adapt itself to the typical operation of industrial facilities characterised by

277 discontinuous VOC emissions. 
279 The variation in the rate of carbon dioxide production with its elimination capacity is shown in Fig. 8a

280 and Fig. 8b for BTF1 and BTF2, respectively. No significant differences were obtained between the

281 bioreactors. An average yield of carbon dioxide of $0.25 \pm 0.09$ and $0.29 \pm 0.09 \mathrm{~g} \mathrm{C} \mathrm{CO}_{2}$ produced per $\mathrm{g} \mathrm{C}$

282 degraded for BTF1 and BTF2 was obtained during the entire experiment, respectively. This value is

283 similar to the data in the literature on treating oxygenated compounds. Sempere et al. [11] obtained an

284 average $\mathrm{CO}_{2}$ yield coefficient between 0.18 and $0.40 \mathrm{~g} \mathrm{C} \mathrm{CO}_{2}$ produced per $\mathrm{g} \mathrm{C}$ degraded treating a

285 mixture of ethanol, ethyl acetate and methyl-ethyl ketone. Other researchers reported carbon

286 mineralisation between $17 \%$ [18] and $46 \%$ [17] treating ethanol.

287 Influence of spraying frequency on the removal of isopropanol

288 As discussed previously, the discontinuous regime of the spraying of the bed resulted in emissions of

289 isopropanol during irrigation, increasing the average outlet concentrations in the emission. A minimum

290 irrigation is required to supply the nutrients, but, due to the high solubility of non-degraded isopropanol in

291 water, the accumulation in the trickling liquid caused a fugitive emission that can be minimised,

292 optimising the frequency of the spraying. The effect of this variable on the average outlet concentration

293 was evaluated for the random packing material. Three regimes of spraying were applied at IL of $32 \mathrm{~g} \mathrm{C}$

$294 \mathrm{~m}^{-3} \mathrm{~h}^{-1}$ and EBRT of $60 \mathrm{~s}$. Figs. $9 \mathrm{a}$ and $9 \mathrm{~b}$ show the results of spraying 15 minutes every 1.5 hours and

295 every 3 hours, respectively, only during the VOC feeding period (16 hours per day). Fig. 9c corresponds

296 to a continuous trickling of 15 minutes every 3 hours over a 24 hours period, including the period without

297 VOC.

299 From Figs. 9a and 9b it can be observed that by decreasing the spraying frequency per day it was possible

300 to reduce the average daily outlet concentration from 86 to $59 \mathrm{~m} \mathrm{C} \mathrm{Nm}^{-3}$ during the VOC feeding period.

301 This decrease in the average daily outlet concentration is related to the fewer peaks of the spraying pattern

302 of 15 minutes every 3 hours. The expansion of spraying at nights (Fig. 9c) caused a decrease in the

303 average outlet emission from 59 to $44 \mathrm{mg} \mathrm{C} \mathrm{Nm}^{-3}$ during the isopropanol feeding period. Spraying during

304 non VOC feeding periods facilitated the VOC transfer to the biofilm and thus enhanced the degradation

305 of the accumulated isopropanol in the water tank. Therefore the transfer from water to the air during 
306 spraying decreases. These results indicated that for the removal of hydrophilic compounds, the spraying

307 frequency is a critical parameter to achieve low emissions under discontinuous and oscillating patterns.

308 Influence of long term starvation on the removal of isopropanol

309 The BTFs were submitted to a starvation period to simulate a holiday industrial closure, in order to

310 evaluate their response after restoring VOC feeding. During the long-term starvation, the air flow rate was

311 maintained at an EBRT of $60 \mathrm{~s}$, and water trickling was set to 15 minutes per day to assure biomass

312 viability conditions. The BTFs were kept under these conditions for up to 7 weeks. The VOC feeding was

313 restored using the same intermittent pattern of 16 hours per day that was applied before the VOC

314 interruption. An IL of around $35 \mathrm{~g} \mathrm{C} \mathrm{m}^{-3} \mathrm{~h}^{-1}$, EBRT of $60 \mathrm{~s}$ and a trickling water of 15 minutes every 4

315 hours was set. The monitoring of the inlet and outlet VOC concentrations of BTF1 and BTF2 is presented

316 in Fig. 10a and Fig. 10b, respectively, once the VOC feeding was restored. As can be observed, REs of 80

$317 \%$ were obtained 5 days after the re-start up for both BTFs. After 10 days of operation, both BTFs

318 achieved REs of $90 \%$, similar values to those obtained in phase B-II, indicating that the performance of

319 the two bioreactors was fully recovered. These results show that the bacterial population can survive in

320 endogenous metabolism for more than 7 weeks if proper adequate operational conditions are adjusted.

321 Zhang and Bishop [20] suggested that extracellular polymeric substances can be a substrate during

322 starving periods. Shorter starvation periods have also been tested on the degradation of other compounds

323 in BTFs. Sempere et al. [11] reported on the successful reacclimation of a BTF degrading a mixture of

324 oxygenated compounds after a 3 week starvation period. Cox and Deshusses [10] found a great

325 reactivation of toluene-degrading BTFs after periods of 2 to 9 days without VOC feeding. The long

326 starvation period tested in this study is of interest due to the fact it has never previously been applied in

327 biotrickling filtration. It demonstrates the sturdiness of the biofiltration techniques to adapt to conditions

328 found in industrial facilities, avoiding the necessity for system re-inoculation with the subsequent saving

329 of costs.

\section{Conclusions}

331 The removal of isopropanol in two biotrickling filters with two packing material of similar specific

332 surface area, one structured and one random, was investigated. Oxygen mass transfer coefficients were

333 determined, showing similar values for liquid velocities up to $15 \mathrm{~m} \mathrm{~h}^{-1}$ at gas velocities of 104 and $312 \mathrm{~m}$ 
$334 \mathrm{~h}^{-1}$. At higher liquid velocities, the structured packing material showed a greater mass transfer coefficient

335 attributed to the different air and water flow paths in both materials. Biotrickling filtration has been

336 shown as an effective technology for the removal of isopropanol in waste gases under intermittent loading

337 conditions (16 hours per day, 5 days per week), typical of industrial sites with night and weekend shut-

338 offs. Stable performance has been obtained with complete removal up to an inlet load of $30 \mathrm{~g} \mathrm{C} \mathrm{m}^{-3} \mathrm{~h}^{-1}$.

339 At high loads, the random packing material showed a slightly higher removal capacity. Due to the low

340 Henry coefficient of isopropanol, it tends to accumulate in the water tank, causing a peak in the outlet

341 emission during intermittent spraying. Thus, this fact indicates that the frequency of irrigation is a crucial

342 parameter to achieve low emissions under intermittent loading of highly soluble compounds. Outlet

343 emissions were reduced by half by decreasing the spraying frequency during isopropanol feeding, and

344 expanding the irrigation to nights and weekends. This strategy allows the minimisation of peak emissions

345 from liquid-mass transfer during isopropanol feeding periods, and promotes the biodegradation of

346 isopropanol accumulated in water during non feeding periods. A fast re-start up after a 7 week starvation

347 period, one of the longest reported, corroborated that biotrickling filtration of soluble compounds under

348 intermittent loading is a robust technology for industrial applications.

\section{Acknowledgements}

350 The research leading to these results has received funding from the People Programme (Marie Curie

351 Actions) of the European Union's Seventh Framework Programme FP7/2007-2013/ under REA grant

352 agreement $n^{\circ}$ 284949. Financial support from the Ministerio de Ciencia e Innovación (Project CTM2010-

353 15031/TECNO) and Generalitat Valenciana (ACOMP/2012/209), Spain, is also acknowledged. Pau San

354 Valero acknowledges the Generalitat Valenciana, Spain (ACIF/2011/067 contract).

\section{References}

356 1. Council Directive 2010/75/EU of 24 November 2010 on industrial emissions (integrated pollution

357 prevention and control). 17.12.2010. Official Journal of European Union

358 2. European Commission (2003) IPPC reference document on best available techniques in common waste

359 water and waste gas treatment/management systems in the chemical sector. Sevilla 
360 3. Devinny JS, Deshusses MA, Webster TS (1999) Biofiltration for air pollution control. CRC-Lewis

361 Publishers, Boca Raton

362 4. Popat SC, Deshusses MA (2010) Analysis of the rate-limiting step of an anaerobic biotrickling filter removing TCE vapors. Process Biochem 45:549-555

364 5. Kirchner K, Wagner S, Rehm HJ (1992) Exhaust-gas purification using biocatalysts (fixed bacteria 365 monocultures) - The influence of biofilm diffusion rate $\left(\mathrm{O}_{2}\right)$ on the overall reaction-rate. Appl Microbiol

366 Biotechnol 37:277-279

367 6. Barton JW, Davison BH, Klasson KT, Gable CC (1999) Estimation of mass transfer and kinetics in

368 operating trickle-bed bioreactors for removal of VOCS. Environ Prog 18:87-92

369 7. Kim S, Deshusses MA (2008) Determination of mass transfer coefficients for packing materials used in

370 biofilters and biotrickling filters for air pollution control. 1. Experimental results. Chem Eng Sci 63:841-

371855

372 8. Chang KS, Lu CS (2003) Biofiltration of isopropyl alcohol by a trickle-bed air biofilter.

373 Biodegradation 14:9-18

374 9. Krailas S, Suppalak T, Meeyoo V (2004) Macrokinetic determination of isopropanol removal using a 375 downward flow biofilter. Songklanakarin J Sci Technol 26:55-64

376 10. Cox HHJ, Deshusses MA (2002) Effect of starvation on the performance and re-acclimation of

377 biotrickling filters for air pollution control. Environ Sci Technol 36:3069-3073

378 11. Sempere F, Gabaldón C, Martínez-Soria V, Marzal P, Penya-Roja JM, Alvarez-Hornos FJ (2008)

379 Performance evaluation of a biotrickling filter treating a mixture of oxygenated VOCs during intermittent

380 loading. Chemosphere 73:1533-1539

381 12. Van't Riet K (1979) Review of measuring methods and nonviscous gas-liquid mass transfer in stirred

382 vessels. Ind Eng Chem Process Des Dev 18:357-364 
383 13. Weiland P, Onken U (1981) Fluid dynamics and mass transfer in an airlift fermenter with external 384 loop. Ger Chem Eng 4:42-50

385 14. Kennes C, Rene ER, Veiga MC (2009) Bioprocesses for air pollution control. J Chem Tech

386 Biotechnol 84:1419-1436

387 15. Clesceri LS, Greenberg AE, Eaton AD (1998) Standard methods for the examination of water and 388 wastewater. American Public Health Association, American Water Works Association and Water

389 Environment Federation, Washington

390 16. Kim S, Deshusses MA (2008) Determination of mass transfer coefficients for packing materials used

391 in biofilters and biotrickling filters for air pollution control - 2: Development of mass transfer coefficients

392 correlations. Chem Eng Sci 63:856-861

393 17. Cox HHJ, Sexton T, Shareefdeen ZM, Deshusses MA (2001) Thermophilic biotrickling filtration of 394 ethanol vapors. Environ Sci Technol 35:2612-2619

395 18. Morotti K, Ramirez AA, Jones JP, Heitz M (2011) Analysis and comparison of biotreatment of air

396 polluted with ethanol using biofiltration and biotrickling filtration. Environ Technol 33:1967-1973

397 19. Sempere F, Gabaldón C, Martínez-Soria V, Penya-Roja JM, Álvarez-Hornos FJ (2009) Evaluation of

398 a combined activated carbon prefilter and biotrickling filter system treating variable ethanol and ethyl

399 acetate gaseous emissions. Eng Life Sci 9:317-323

400 20. Zhang XQ, Bishop PL (2003) Biodegradability of biofilm extracellular polymeric substances.

401 Chemosphere 50:63-69

402

403 
405 Table 1 Experimental plan for the removal of isopropanol under intermittent loading conditions

\begin{tabular}{|c|c|c|c|c|c|}
\hline & & Days & $\mathrm{C}_{\mathrm{in}}\left(\mathrm{mg} \mathrm{C} \mathrm{Nm}^{-3}\right)$ & $\operatorname{IL}\left(\mathrm{g} \mathrm{C} \mathrm{m}^{-3} \mathrm{~h}^{-1}\right)$ & EBRT (s) \\
\hline \multirow[t]{3}{*}{ Phase A } & A-I & $0-48$ & 1000 & 20 & 160 \\
\hline & A-II & $49-69$ & 1000 & 35 & 90 \\
\hline & A-III & $70-90$ & 1000 & 65 & 50 \\
\hline \multirow[t]{3}{*}{ Phase B } & B-I & $91-97$ & 500 & 20 & 90 \\
\hline & B-II & 98-104 & 500 & 35 & 50 \\
\hline & B-III & $105-125$ & 500 & 65 & 25 \\
\hline \multirow[t]{2}{*}{ Phase C } & C-II & $126-132$ & 250 & 35 & 25 \\
\hline & C-III & $133-163$ & 250 & 65 & 14 \\
\hline
\end{tabular}


407 Table 2 Quality of trickling water during the whole experiment

\begin{tabular}{|c|c|c|c|c|}
\hline & \multicolumn{2}{|c|}{ BTF1 } & \multicolumn{2}{|c|}{ BTF2 } \\
\hline & Average & Std Dev & Average & Std Dev \\
\hline $\mathrm{pH}$ & 8.91 & 0.23 & 9.01 & 0.23 \\
\hline Conductivity $\left(\mathrm{mS} \mathrm{cm}^{-1}\right)$ & 5.22 & 1.33 & 5.23 & 1.14 \\
\hline Nitrate conc. $\left(\mathrm{mg} \mathrm{N} \mathrm{L}^{-1}\right)$ & 30 & 23 & 38 & 33 \\
\hline Soluble COD $\left(\mathrm{mg} \mathrm{L}^{-1}\right)$ & 1200 & 498 & 1107 & 540 \\
\hline
\end{tabular}

408

409

410

411

412

413 


\section{$414 \quad$ Figure Captions}

415 Fig. 1 Schematic of the experimental set-up for the determination of $\mathrm{k}_{\mathrm{L}} \mathrm{a}$

416 Fig. 2 Schematic of the experimental set-up for the elimination of isopropanol

417 Fig. 3 Influence of superficial liquid velocity on the oxygen mass transfer coefficient in BTFs

418 Fig. 4 Influence of superficial gas velocity on the oxygen mass transfer coefficient for the structured

419 packing material

420 Fig. 5 Outlet pattern emission during 24 hours monitoring of the biotrickling filtration of isopropanol

421 under intermittent loading conditions for BTF2 a) Phase A-III b) Phase B-II

422 Fig. 6 Performance of the BTFs on the removal of isopropanol. Discontinuous line represents a 1.8 step

423 increase in the inlet load a) BTF1 b) BTF2

424 Fig. 7 Isopropanol elimination capacity versus inlet load a) BTF1 b) BTF2

425 Fig. 8 Production of carbon dioxide versus elimination capacity of isopropanol a) BTF1 b) BTF2

426 Fig. 9 Influence of the spraying regime on the outlet pattern emission a) spraying 15 minutes every 1.5

427 hours during VOC feeding period b) spraying 15 minutes every 3 hours during VOC feeding period c) 15

428 minutes every 3 hours during 24 hours

429 Fig. 10 Performance of the BTFs on the removal of isopropanol after 7 weeks of starvation a) BTF1 b)

$430 \quad$ BTF2

431 


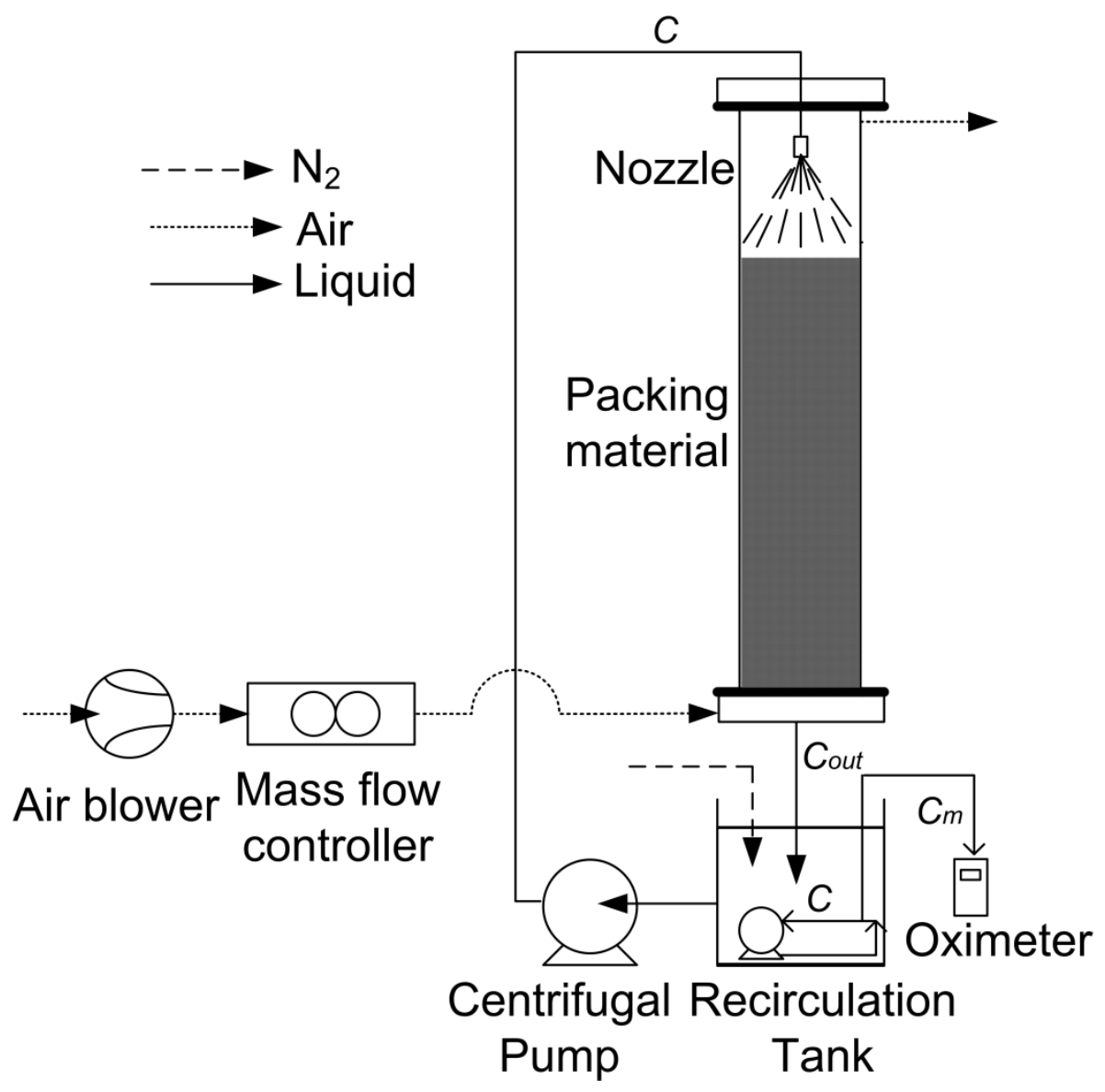

434 
435 Fig. 2 Schematic of the experimental set-up for the elimination of isopropanol

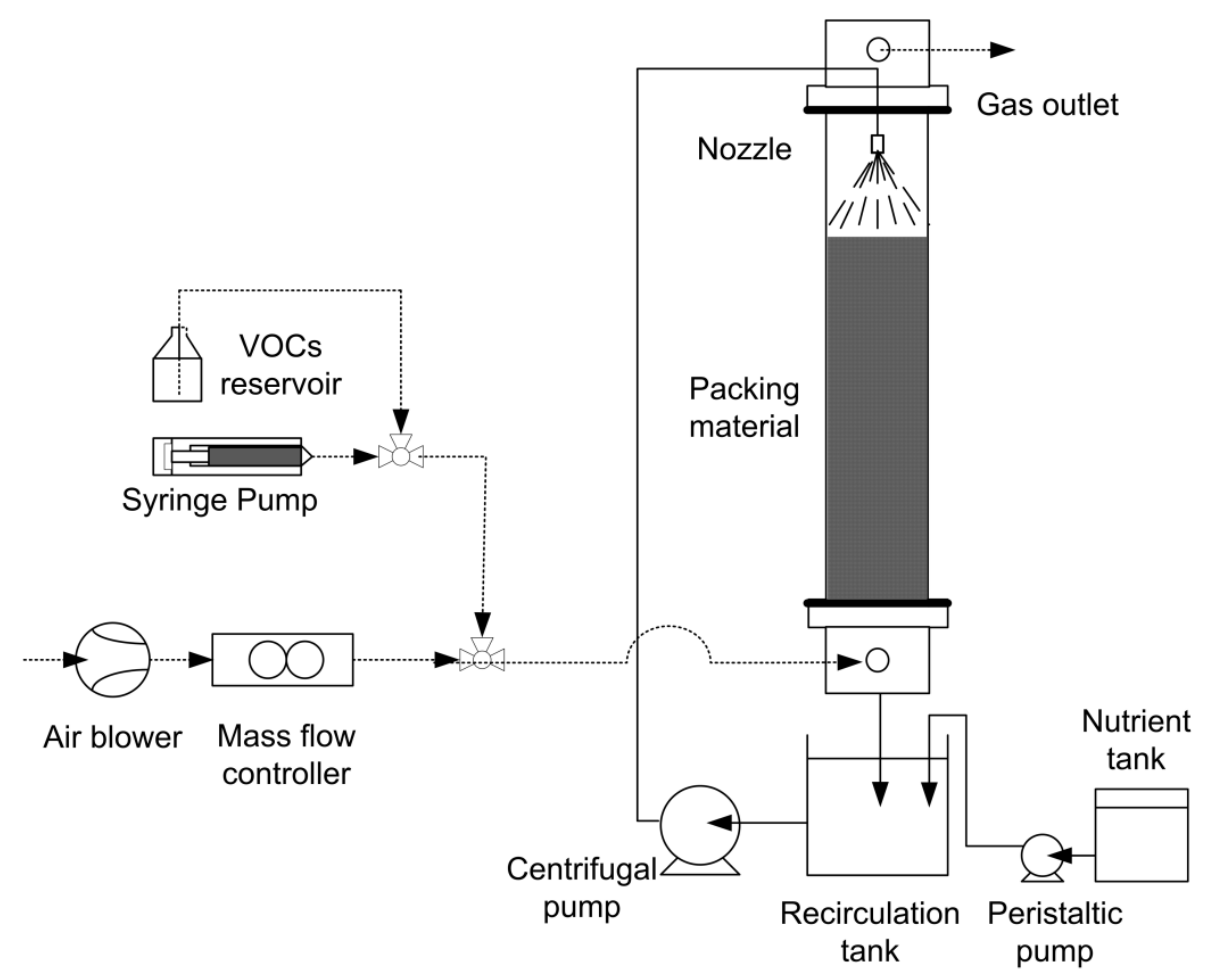

437 


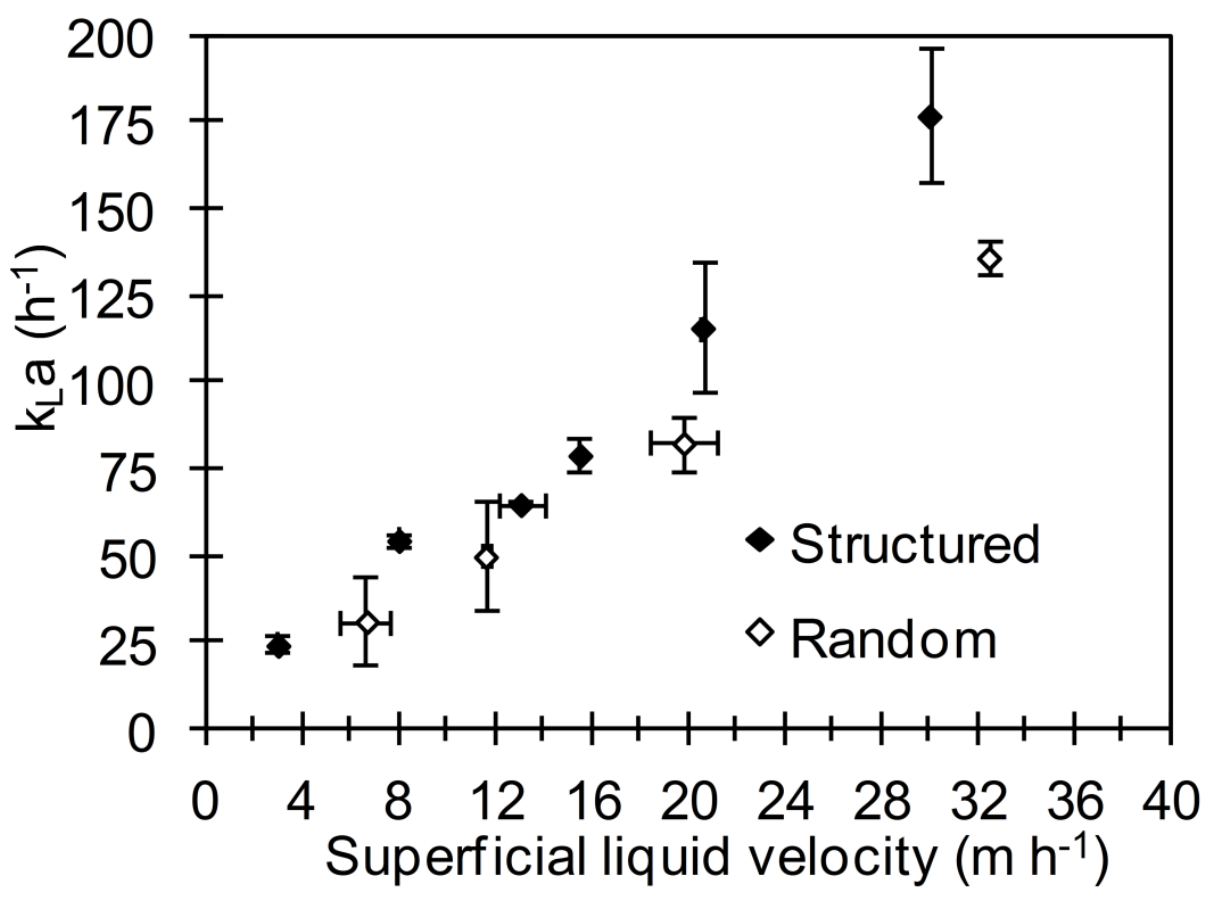

440 


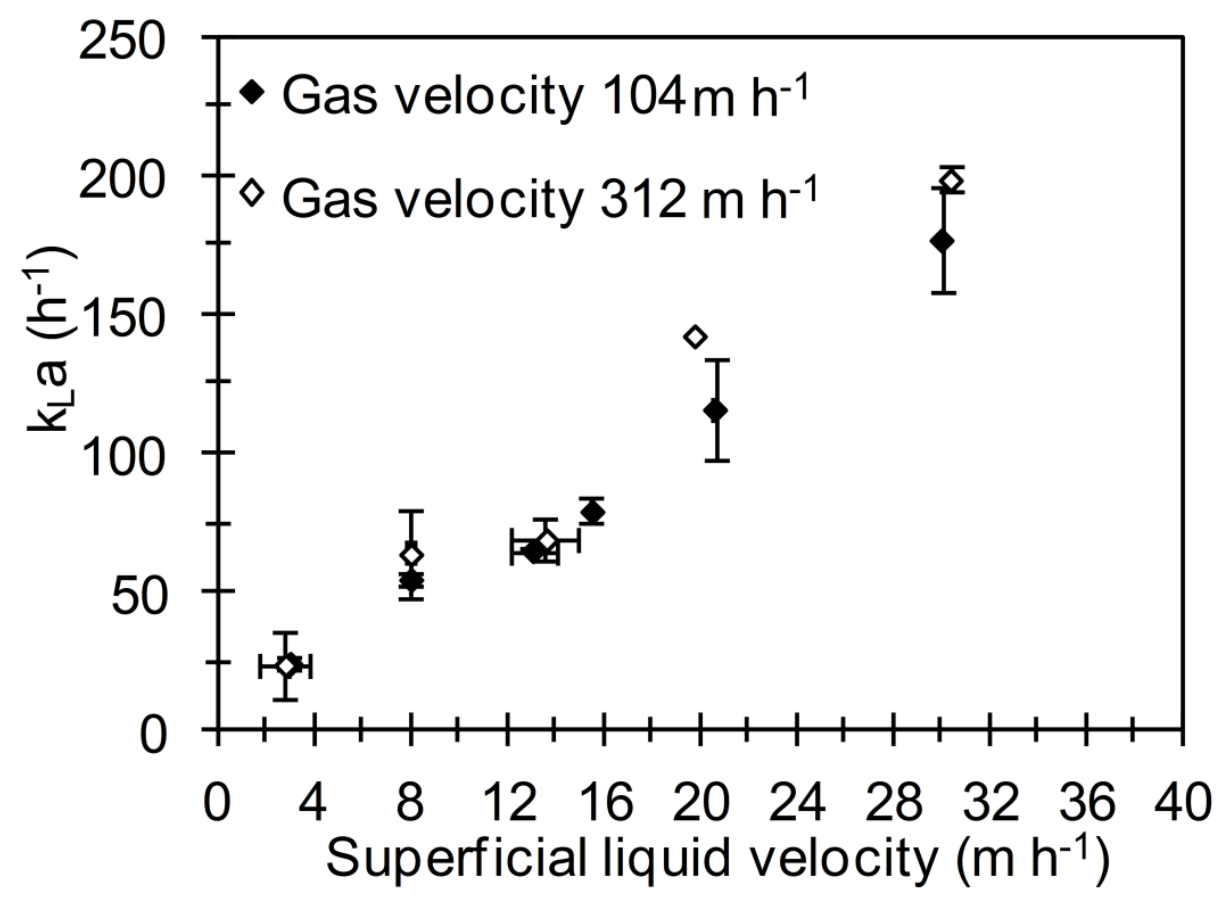

443

444 

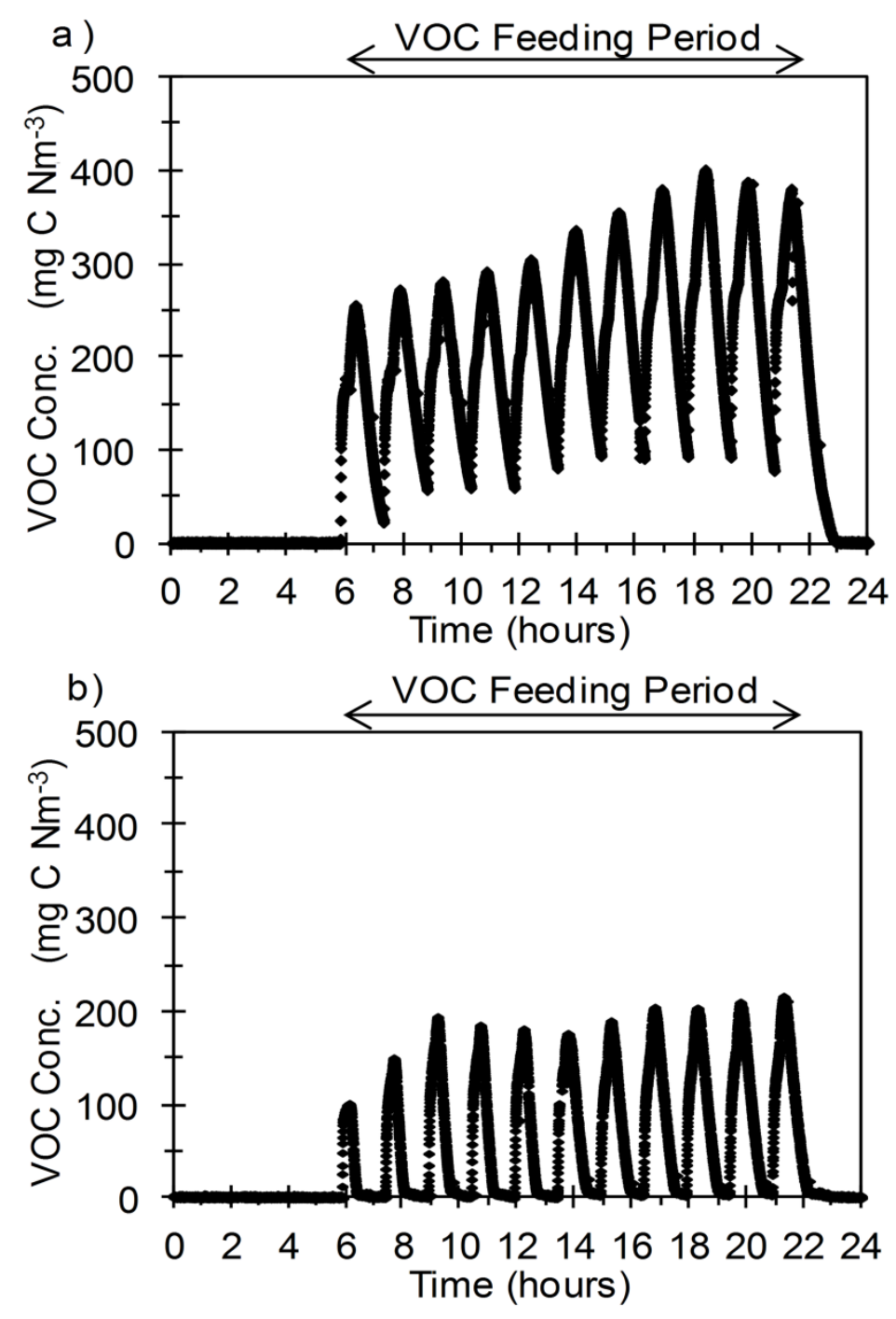

447 

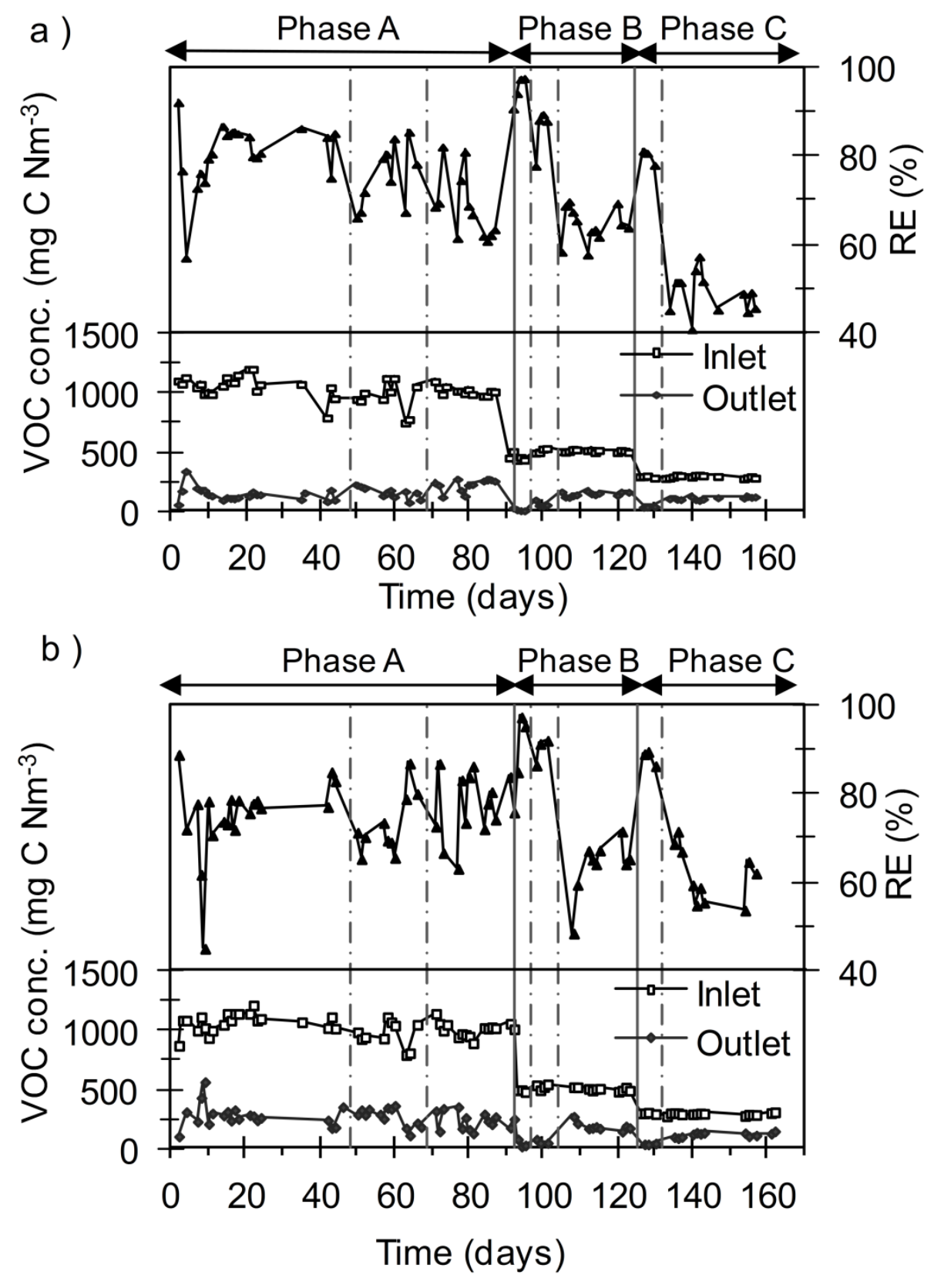
a)

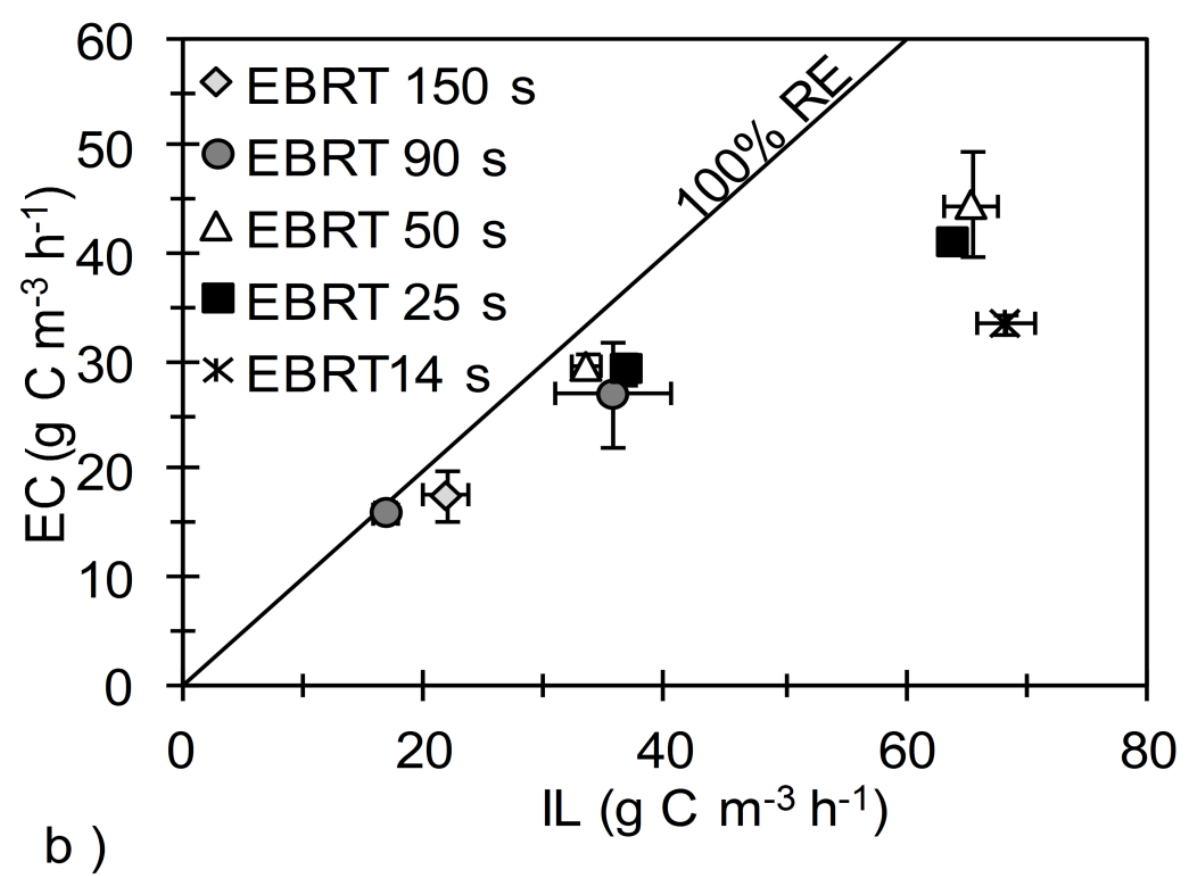

454

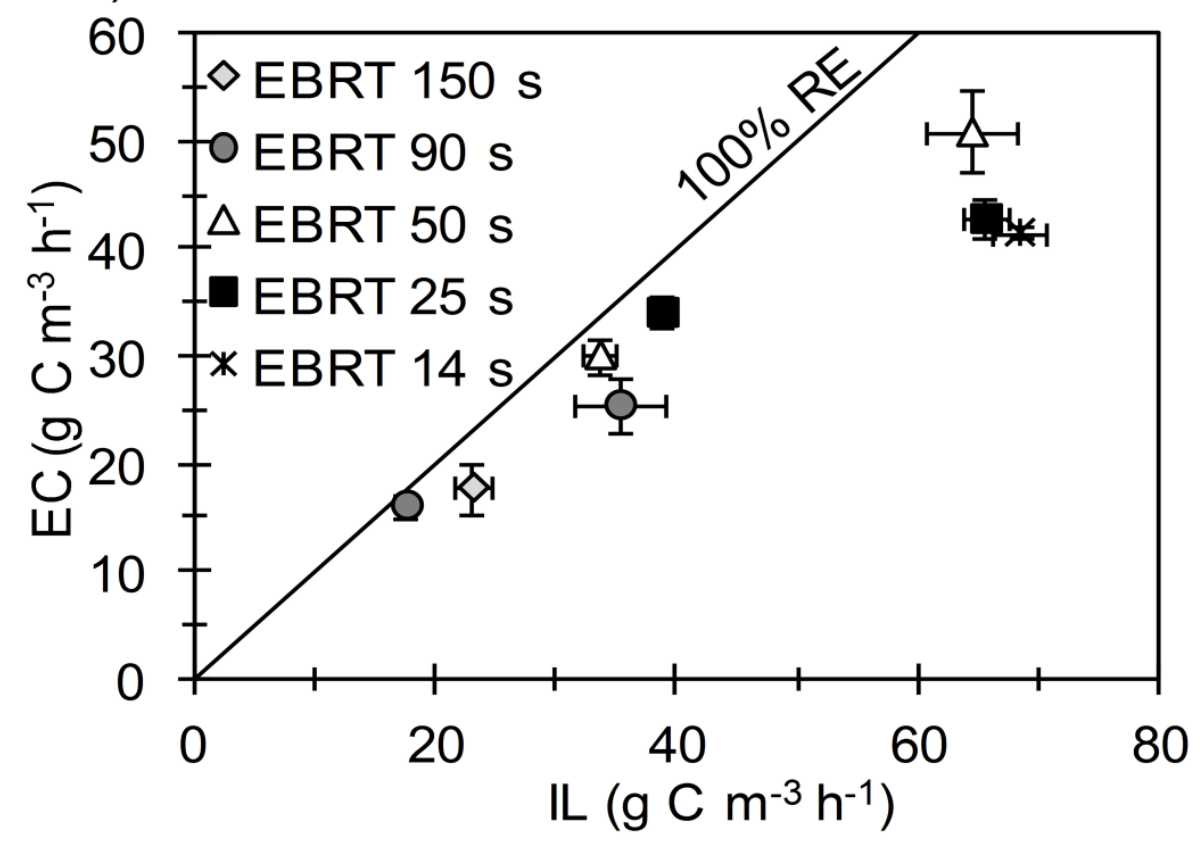


a)

460 hours during VOC feeding period b) spraying 15 minutes every 3 hours during VOC feeding period c) 15

461 minutes every 3 hours during 24 hours
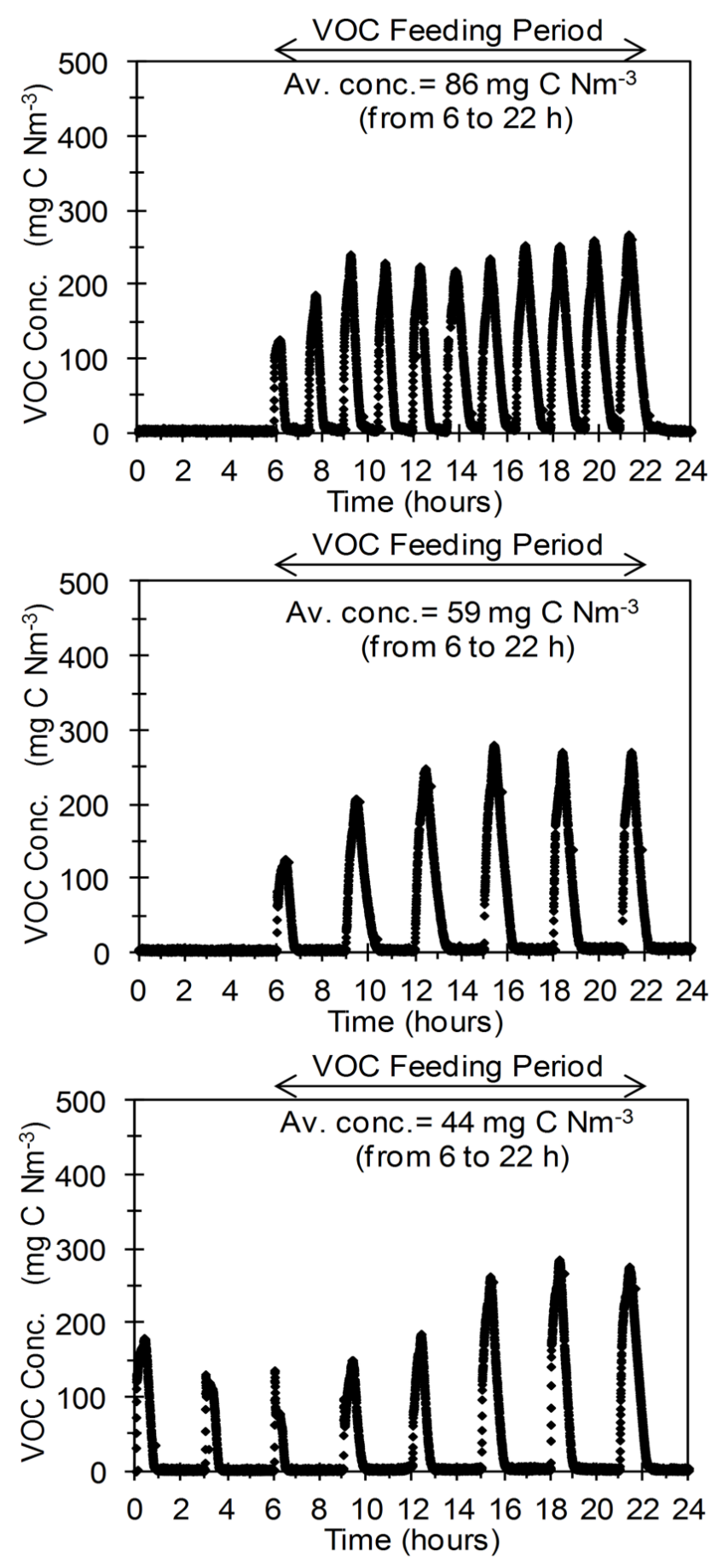

462 
464 Fig. 10 Performance of the BTFs on the removal of isopropanol after 7 weeks of starvation a) BTF1 b) 465 BTF2

a)

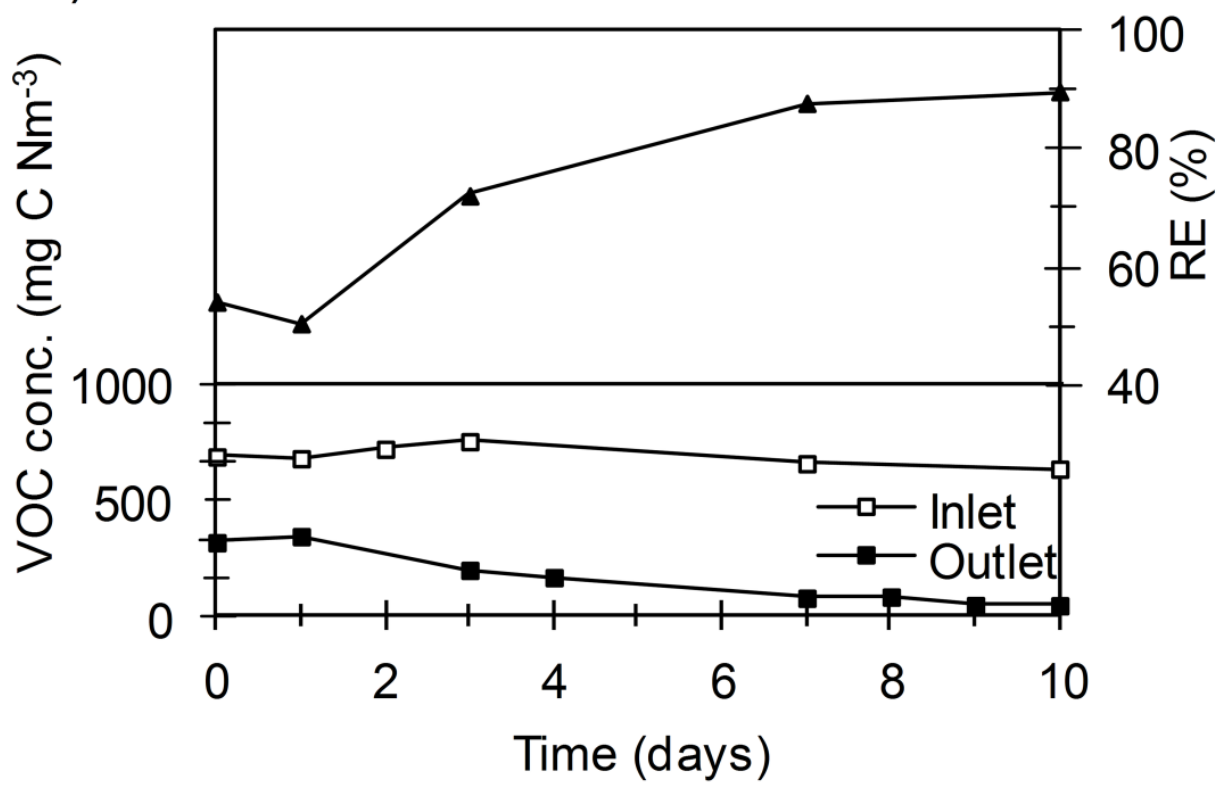

b)

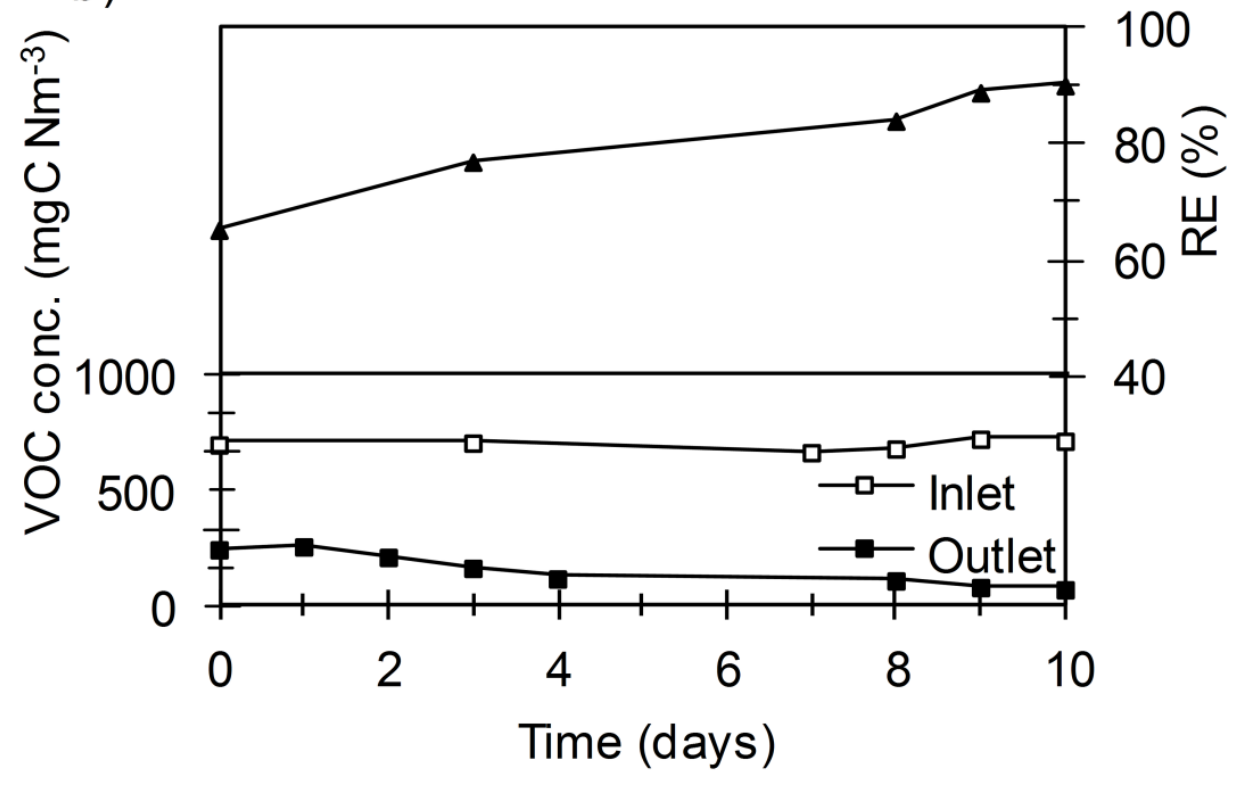

466 